\title{
Order in Antarctic ice streams
}

Ice streams transport ice rapidly from the interior of the Antarctic ice sheet to the coast. An analysis of surface flow convergence suggests that ice flow and geometry are intricately linked within these ice streams.

\section{O. V. Sergienko}

nterspersed throughout the margins of Earth's ice sheets are areas of fast

flowing ice, known as ice streams ${ }^{1}$. With their rapid motion, ice streams are the main pathways for ice discharge from the interior of an ice sheet to the surrounding ocean. Conditions at the base of the ice stream probably support their fast flow, but relatively little is known about what controls the spatial structure of ice streams, how ice-stream networks form, and how neighbouring ice streams interact. Writing in Nature Geoscience, Felix $\mathrm{Ng}^{2}$ reports a new approach to analysing surface flow of ice sheets that hints at how ice-stream networks form and develop.

The factors controlling the formation and evolution of ice streams are expected to arise from the interface between the ice and the bed; however, direct access to the base is only available at a few locations. The flow of ice itself may provide some clues about the ice stream/base interface. As ice flows over complicated topography, and in areas with large variation in basal traction, the speed and direction of flow change. Traditionally, it is the surface velocity of the ice flow that is used to make inferences about basal conditions ${ }^{3}$.

$\mathrm{Ng}^{2}$ proposes that the direction of ice flow is equally important for understanding the spatial organization of ice streams. He introduces the concept of the ice-surface flow convergence, $C$, which is defined as the rate of change of the direction of movement across the flow. If flow is converging, then $C$ is positive, if flow is diverging $C$ is negative, and if flow does not experience variations in its direction $C$ is 0 . (Fig. 1). As opposed to speed-based measures, the use of convergence can capture dynamics in areas where ice flow is slow, because convergence is proportional to the crossflow compressive strain rate, which is determined by the velocity gradients, and therefore has large variations even though the magnitudes of ice speed are small.

Using high-resolution remote sensing observations of the Antarctic ice sheet surface velocities ${ }^{4}, \mathrm{Ng}$ computes convergence of the Antarctic ice sheet surface flow, which reveals the

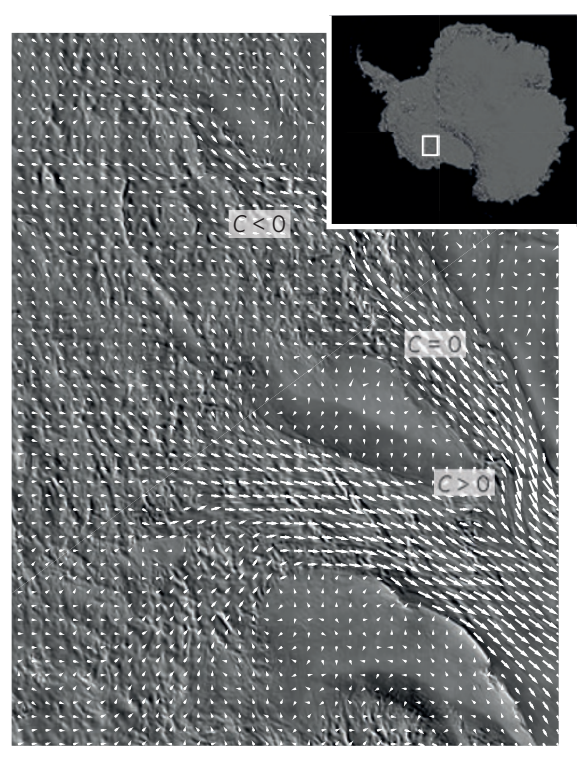

Figure 1| Antarctic flow patterns. Ng shows that characterizing flow across Antarctica in terms of convergence can identify patterns of flow and help to better understand conditions at the base of the ice flow. The MacAyeal and Bindschadler ice streams exhibit convergent $(C>0)$, divergent $(C<0)$ and plug flow $(C=0)$. White arrows are vectors of surface ice flow ${ }^{4}$. Inset, satellite image of Antarctica with white rectangle indicating the area shown in the main image. MODIS images from ref. 8, NSIDC.

morphological structure of ice streams. The convergence map shows a clear treelike spatial organization of the Antarctic ice streams, revealing how flow from the interior of the Antarctic ice sheet is arranged into networks that discharge ice into ice shelves and ultimately into the Southern Ocean. But it is not only this structure that is exposed in the map of convergence: the map also identifies irregularities in ice flow over rough topography ${ }^{5}$, alternations of areas of high and low basal traction ${ }^{6}$ and variability in ice viscosity ${ }^{7}$ associated with ice temperatures and fabric. The spatial pattern of convergence flow is strikingly bimodal. Areas with slow flow exhibit strong, smallscale variability of convergence on the order of few kilometres, which Ng terms 'chaos regions'. Areas with faster ice flow exhibit convergence variability on scales of several tens of kilometres. On the ice shelves convergence hardly varies at all. The latter two types of regions are defined as 'streaming regions'.

$\mathrm{Ng}$ further analysed the relationship between convergence and previously calculated flow speed. He found that regardless of the location - ice streams, margins, tributaries - ice speed and flow convergence show a similar relationship. This suggests that the geometry of tributaries and other ice-stream network structures are linked to ice flow through a common physical mechanism. In other words, it indicates that the geometric characteristics of tributaries and ice streams and their flow are not independent, and that both are strongly constrained by the process that routes ice flow through this network.

Using this measure of convergence, $\mathrm{Ng}^{2}$ provides evidence that ice stream geometry and flow speed are physically linked. The proposed use of convergence of the ice sheet surface flow opens new avenues for exploring the complex patterns of continental-scale ice sheet flow, and paves the way to identifying the underlying physics that control development of ice stream networks.

O. V. Sergienko is at the Program in Atmospheric and Oceanic Sciences, Princeton University, 201 Forrestal Road, Princeton, New Jersey 08540, USA. e-mail:osergien@princeton.edu

\footnotetext{
References

1. Rose, K. J. Glaciol. 24, 63-76 (1979).

2. Ng, F. S. L. Nature Geosci. 8, 847-850 (2015).

3. MacAyeal, D. R. J. Geophys. Res. 97, 595-603 (1992)

4. Rignot, E., Mouginot, J. \& Scheuchl, B. Science 333, 1427-1430 (2011).

5. Gudmundsson, G. H. J. Geophys. Res. 108, 2253 (2003).

6. Sergienko, O. V. \& Hindmarsh, R. C. A. Science 342, 1086-1089 (2013).

7. Hulbe, C. L. \& Whillans, I. M. J. Glaciol. 43, 377-386 (1997)

8. Haran, T., Bohlander, J., Scambos, T., Painter, T. \& Fahnestock. M. MODIS Mosaic of Antarctica 2008-2009 MOA2009 (National Snow and Ice Data Center, 2014); http://dx.doi.org/10.7265/ N5KP8037
}

Published online: 16 September 2015 